\title{
High prevalence of cardiovascular risk factors in children and adolescents with type 1 diabetes: a population-based study
}

\author{
H. D. Margeirsdottir • J. R. Larsen • C. Brunborg • \\ N. C. Øverby • K. Dahl-Jørgensen • \\ the Norwegian Study Group for Childhood Diabetes
}

Received: 4 October 2007 /Accepted: 7 December 2007 /Published online: 15 January 2008

(C) Springer-Verlag 2007

\begin{abstract}
Aims/hypothesis The risk of dying of cardiovascular disease (CVD) before the age of 40 years is increased nearly 20 -fold in patients with type 1 diabetes compared with nondiabetic persons. The aim of this study was to evaluate the prevalence of CVD risk factors in a population-based study of children and adolescents with type 1 diabetes.

Methods CVD risk factors were examined according to the American Diabetes Association criteria in 2005. Of 26 paediatric clinics in Norway, 25 participated with 1,658 patients, $85 \%$ of those eligible. Mean age was 13.1 years and mean diabetes duration 5.7 years.

Results $\mathrm{HbA}_{1 \mathrm{c}}$ was above the target level in $71.4 \%$. A positive family history of early CVD and/or diabetes was found in $33 \%$ of participants. LDL-cholesterol was $>2.6 \mathrm{mmol} / 1$ in $34.5 \%$ and HDL-cholesterol was $<1.1 \mathrm{mmol} / 1$ in $6.9 \%$ of participants. Blood pressure was above the 90th percentile by
\end{abstract}

H. D. Margeirsdottir · J. R. Larsen · K. Dahl-Jørgensen

Faculty of Medicine, University of Oslo,

Oslo, Norway

H. D. Margeirsdottir $(\bowtie) \cdot J$. R. Larsen $\cdot K$. Dahl-Jørgensen Department of Paediatrics, Ullevaal University Hospital, 0407 Oslo, Norway

e-mail: h.d.margeirsdottir@medisin.uio.no

H. D. Margeirsdottir · J. R. Larsen · K. Dahl-Jørgensen Diabetes Research Centre, Aker and Ullevaal University Hospitals, and Faculty of Medicine, University of Oslo, Oslo, Norway

C. Brunborg

Centre for Clinical Research, Ullevaal University Hospital,

Oslo, Norway

N. C. Øverby

Department of Nutrition, Institute of Basic Medical Sciences, Faculty of Medicine, University of Oslo,

Oslo, Norway age, sex and height in 7\% and above the 95th percentile in $4 \%$ of participants. Four per cent of participants were obese, $3 \%$ of those $\geq 12$ years of age reported smoking and $1 \%$ of all participants had persistent microalbuminuria. Only $0.2 \%$ of the patients were receiving statin and $0.3 \%$ antihypertensive treatments. Dietary habits and physical activity level were evaluated in some patients. Almost all had higher intake of dietary fat and lower intake of fibre than recommended. A large part was less active and watched more TV than recommended.

Conclusions/interpretation Of the participants, $86 \%$ had at least one, $45 \%$ at least two and $15 \%$ at least three CVD risk factors. Few patients were treated with statins and antihypertensive drugs.

Keywords Adolescents - Cardiovascular disease . Cardiovascular risk factors $\cdot$ Children $\cdot \mathrm{CVD} \cdot \mathrm{Diet} \cdot \mathrm{HbA}_{1 \mathrm{c}}$. Lipids · Physical activity · Type 1 diabetes

$\begin{array}{ll}\text { Abbreviations } \\ \text { ADA } & \text { American Diabetes Association } \\ \text { CRF } & \text { case record form } \\ \text { CVD } & \text { cardiovascular disease } \\ \text { DBP } & \text { diastolic blood pressure } \\ \text { ISPAD } & \text { International Society for Pediatric and } \\ & \text { Adolescent Diabetes } \\ \text { NCDQ } & \text { Norwegian Childhood Diabetes and Quality Project } \\ \text { SBP } & \text { systolic blood pressure } \\ \text { WCH } & \text { white coat hypertension }\end{array}$

\section{Introduction}

The major cause of morbidity and mortality in people with type 1 diabetes is premature and extensive atherosclerosis 
and cardiovascular disease (CVD). Several studies have shown that mortality from CVD is increased two- to 20 -fold in type 1 diabetic patients [1-3], while CVD has now overtaken diabetic nephropathy as the leading cause of premature death in young adults with diabetes $[1,2]$. The prevalence of CVD in this population points to the importance of early identification of known CVD risk factors and early intervention [1].

In addition to studies in non-diabetic participants, demonstrating that cardiovascular risk factors are identifiable in childhood and that they predict risk of adulthood CVD [4-6], epidemiological studies in adults have also shown that multiple risk factors increase the probability of cardiovascular events, since cardiovascular risk factors tend to reinforce each other in their influence on morbidity and mortality [5]. Furthermore, the progression of atherosclerotic disease and the severity of atherosclerosis relate not only to the presence and extent of cardiovascular risk factors, but also to the persistence of risk factors over time [5, 7].

Children with diabetes are already at increased risk of early $\mathrm{CVD}$, since diabetes is now recognised as an independent risk factor for future cardiovascular events, equivalent to having had a previous myocardial infarction $[3,8]$.

The aim of this study was to evaluate the prevalence of cardiovascular risk factors in children and adolescents with type 1 diabetes in Norway.

\section{Methods}

Study population The study was performed as a part of the Norwegian Childhood Diabetes and Quality project (NCDQ) [9], which is a prospective population-based study for research and quality improvement by means of benchmarking, and includes all children and adolescents with type 1 diabetes in Norway.

The classification of type 1 diabetes mellitus is ensured by measurements of auto antibodies [insulin, GAD, tyrosine phosphatase-like insulinoma antigen 2 (IA-2)] and C-peptide at diagnosis. Children with type 2 diabetes mellitus were excluded. Diagnosis of type 1 diabetes was made according to the American Diabetes Association (ADA) and International Society for Pediatric and Adolescent Diabetes (ISPAD) criteria.

The CVD risk factor analysis was based on data collected in 2005 . Of 26 paediatric clinics in Norway, 25 participated in the NCDQ study that year. The mean overall adherence rate was $85 \%$ (between-hospital range $41-99 \%$ ) with 20 clinics reporting on more than $80 \%$ of their patients.

All patients in the NCDQ were invited to participate in a study on physical activity and dietary habits in 2004 and 2005. Of the patients participating in the NCDQ project in 2005, 576 children and adolescents answered question- naires about physical activity and sedentary behaviour, 376 in 2004 and 200 in 2005. This gives a participation rate of $35 \%$. A total of 518 had recorded their diet for 4 days, a participation rate of $31 \%$.

The study protocols were approved by the National Committee for Research Ethics in Norway and the Norwegian Social Science Data Services. Written informed consent was obtained from the parents and from the participants, when older than 12 years of age.

Procedures All diabetic children in Norway are treated at the paediatric clinics of the public hospitals. An extended and standardised examination is done on all patients at each clinic, every year.

Data were collected from a case record form (CRF) translated and modified from the WHO Basic Information Sheet for children and adolescents. The CRF includes detailed information about the insulin regimen (insulin type and dose), acute and chronic complications, age, height, weight, puberty stages (Tanner), BP and smoking habits, together with a family history (first and second-degree relatives) of diabetes and CVD.

The collection of data on dietary and physical activity was carried out simultaneously from January to April 2004 and 2005. The dietary data collection is described in detail elsewhere [10]. The participants recorded their food intake for 4 days using food diaries with a photographic booklet, which contained pictures of portion sizes [10]. The diary has been validated in 9- and 13-year olds and was found to be a useful tool to estimate dietary intake in this population [11]. Those who participated in the study on physical activity and sedentary behaviour filled in a questionnaire, which included questions about school time and leisure time physical activity, as well as sedentary behaviour such as television viewing and use of personal computers, among others [12]. The questionnaire used for this analysis is standardised and evaluated against the ActiReg physical activity monitor (PreMed, Oslo, Norway) [13]. The questionnaire gives information about activity pattern, active time, inactive time and activity intensity; it also allows total energy expenditure to be calculated [12].

CVD risk factors New clinical practice recommendations were published by the ADA in January 2005 [14]. The ADA recommendations for children and adolescents with diabetes include modifications in response to the higher cardiovascular risk status of these patients. The CVD risk factor analysis in our study was done according to these ADA guidelines. The ADA guidelines on diet and physical activity are not very detailed, but refer to other guidelines, e.g. those of the American Heart Association and Centers of Disease Control, as well as the ADA technical review and positional statement for this area. The cut-off values in our 
diet and physical activity analysis are therefore based on international guidelines including those of the Centers of Disease Control, the ISPAD consensus guidelines and ADA guidelines [15-20].

Laboratory methods $\mathrm{HbA}_{1 \mathrm{c}}$ was determined for all patients by high-performance liquid chromatography (Variant; BioRad, Richmond, CA, USA) at the same central DCCTapproved laboratory at the clinical chemistry department of Aker University Hospital, Oslo, Norway. The normal reference range was $4.1-6.4 \%(2 \mathrm{SD})$ and the intra-assay coefficient of variation was $<3 \%$.

Lipid profiles were measured by conventional methods in the non-fasting state. Lipid measurements were done locally, at each hospital participating in the study, of which nine ( $n=498$ participants) used direct measurements for measuring LDL-cholesterol, while 16 of them $(n=1160$ participants) used indirect measurement (estimated by the Friedewald formula).

Definitions In defining overweight, weight and height were used to calculate BMI $\left(\mathrm{kg} / \mathrm{m}^{2}\right)$. The international BMI cutoff points that were used to estimate the prevalence of overweight were based on centile curves defined to pass through a BMI of $25 \mathrm{~kg} / \mathrm{m}^{2}$ at age 18 years in a survey of six nationally representative growth studies conducted by Cole et al. [21].

Blood pressure was measured according to the National High Blood Pressure Education Program Working Group on High Blood Pressure in Children and Adolescents [22]. Standardisation of measurements was secured in network meetings of the health personnel involved. Identical procedures and standardised tables of $\mathrm{BP}$ centiles (BP standards based on sex, age and height) were used in all departments [22] to estimate whether BP was above the 90th or 95th percentile. This was done by the responsible health personnel at each clinic and marked off in the CRF.

Target levels for $\mathrm{HbA}_{1 \mathrm{c}}$ were defined as $\mathrm{HbA}_{1 \mathrm{c}}<7.5 \%$ in children and adolescents above 12 years of age, $<8 \%$ in children aged 6 to 12 years and $<8.5 \%$ in children younger than 6 years of age.

Recommendations for physical activity in this age group are $60 \mathrm{~min}$ of moderate to vigorous activity [ $>3$ metabolic equivalents of the task (METs)] per day [14, 17], which was used as a cut-off to identify diabetic children and adolescents fulfilling or not fulfilling this recommendation. Sedentary activity includes time spent on homework, reading, watching television and using personal computers.

Intensive insulin treatment was defined as using an insulin pump or using three or more injections per day.

Statistical analysis Demographical and clinical data are presented as mean values with $\mathrm{SD}$ or as proportions.
Differences in continuous variables between males and females were tested with an independent sample $t$ test and by Pearson's $\chi^{2}$ test for categorical variables.

All $p$ values are two-sided and a 5\% significance level was used. All statistical analyses were performed using the SPSS software package for Windows version 14.0 (SPSS, Chicago, IL, USA).

\section{Results}

Patient characteristics We included 1,658 patients in the study. Mean age was 13.1 years (range 1.1-23.2 years), while mean diabetes duration was 5.7 years (range 0.618.5 years). The vast majority of the patients were using intensive insulin treatment. We have information about the insulin regimen in $92 \%$ of the patients $(n=1,528$; patients with missing data $n=130)$. Of these, $95 \%(n=1,450)$ were using three or more insulin injections daily or insulin pumps. Selected characteristics of the participants are presented in Table 1 and show that there were no differences between boys and girls.

Smoking was reported by $2 \%$ of all the patients, $3 \%$ of those aged $>12$ years and $5 \%$ of those aged $>15$ years. The mean age of the smokers was 17.4 years and the youngest smoker was 14 years.

The BP (systolic and/or diastolic) was above the 90th percentile by age, sex and height in $7 \%$ and above the 95 th percentile in $4 \%$ of participants. The results are shown in Tables 2 and 3. Of those with elevated BP (above 90th percentile), 72\% had elevated systolic BP (SBP), 7\% elevated diastolic BP (DBP) and 21\% had both SBP and DBP elevated.

There was no difference between boys and girls with regard to the proportion of patients per risk factor, except for LDL-cholesterol and HDL-cholesterol, where a higher proportion of the girls had LDL-cholesterol $>2.6 \mathrm{mmol} / \mathrm{l}$ $(p=0.001)$ and a higher proportion of the boys had HDLcholesterol $<1.1 \mathrm{mmol} / 1$ ( $p=0.001)$.

The mean triacylglycerol value was $1.0 \mathrm{mmol} / \mathrm{l}$. Patients with LDL-cholesterol $>2.6 \mathrm{mmol} / \mathrm{l}$ had a mean triacylglycerol value of $1.1 \mathrm{mmol} / \mathrm{l}$. In the NCDQ project it is recommended that fasting lipid values are measured if nonfasting lipids are above certain values. For patients with both fasting and non-fasting values $(n=50)$, the mean fasting and non-fasting levels were: $1.3 \mathrm{mmol} / \mathrm{l}$ and $1.4 \mathrm{mmol} / \mathrm{l}$, respectively, for triacylglycerol; $3.4 \mathrm{mmol} / \mathrm{l}$ and $3.3 \mathrm{mmol} / 1$, respectively, for LDL-cholesterol; and $1.7 \mathrm{mmol} / \mathrm{l}$ and $1.8 \mathrm{mmol} / \mathrm{l}$, respectively, for HDL-cholesterol. In other words, there was no significant difference between fasting and non-fasting values in this group of patients. 
Table 1 Characteristics of participants

\begin{tabular}{lcccc}
\hline & Boys & Girls & All patients & Dietary and physical activity study cohort \\
\hline$n$ & 872 & 786 & 1,658 & 576 \\
Age (years) & $13.3(3.9)$ & $13.4(3.6)$ & $13.1(3.8)$ & $13.6(2.9)$ \\
Diabetes duration (years) & $5.9(3.6)$ & $5.6(3.3)$ & $5.7(3.5)$ & $5.9(3.2)$ \\
Puberty stage (Tanner) & $2.7(1.7)$ & $2.8(1.6)$ & $2.8(1.6)$ & $2.8(1.6)$ \\
${\text { BMI }\left(\mathrm{kg} / \mathrm{m}^{2}\right)}$ ) & $20.2(3.8)$ & $20.2(3.9)$ & $20.2(3.8)$ & $20.3(3.7)$ \\
$\mathrm{HbA}_{1 \mathrm{c}}(\%)$ & $8.2(1.3)$ & $8.2(1.2)$ & $8.2(1.2)$ & $8.1(1.2)$ \\
Insulin dose (U/kg body weight) & $0.9(0.3)$ & $0.9(0.3)$ & $0.9(0.3)$ & $0.9(0.3)$ \\
Insulin regimen, $n(\%)$ & & & $77(4.5)$ & $23(4.0)$ \\
One to two injections per day & $38(4.4)$ & $37(4.7)$ & $191(11.5)$ & $55(9.5)$ \\
Three injections per day & $112(12.8)$ & $79(10.1)$ & $662(39.9)$ & $212(36.8)$ \\
Four or more injections per day & $349(40.0)$ & $313(39.8)$ & $597(36.0)$ & $243(42.2)$ \\
Insulin pump, $n(\%)$ & $313(35.9)$ & $284(36.1)$ & &
\end{tabular}

Unless otherwise stated, values are mean (SD)

a Patients with missing data $n=130$

Questions about physical activity and sedentary behaviour were answered by 576 patients, while 518 patients recorded their diet for 4 days. This gives a participation rate of 35 and $31 \%$, respectively. Participants in the physical activity and dietary analyses were slightly but significantly older $(0.4$ years $)(p<0.001)$ and also had slightly but significantly lower $(0.1 \%) \mathrm{HbA}_{1 \mathrm{c}}(p=0.006)$ than nonparticipants. Otherwise, the characteristics of participants and non-participants were similar (Table 1). The results from the physical activity and dietary study are shown in Table 3.

Number of cardiovascular risk factors Overall, $86 \%$ of the patients had at least one of the risk factors for CVD, $45 \%$ had two or more risk factors, $15 \%$ three or more risk factors and $2 \%$ had four risk factors or more (Table 2). Physical activity, sedentary activity and dietary habits were not included in the multiple risk factor analysis, as not all patients had participated, but only selected cohorts. However, if these factors had been included, the overall frequency of CVD risk factors would have increased substantially.

The three most common combinations of two CVD risk factors were: (1) $\mathrm{HbA}_{1 \mathrm{c}}$ and LDL-cholesterol above target levels; (2) $\mathrm{HbA}_{1 \mathrm{c}}$ above target level and family history of type 2 diabetes; (3) family history of both type 2 diabetes and CVD. The three most common combinations of three CVD risk factors were: (1) $\mathrm{HbA}_{1 \mathrm{c}}$ above target level and family history of both type 2 diabetes and CVD; (2) $\mathrm{HbA}_{1 \mathrm{c}}$ and LDL-cholesterol above target levels, plus a family

Table 2 CVD risk factors (as defined by the ADA)

\begin{tabular}{|c|c|c|c|c|c|}
\hline Risk factors & References & Boys $(n=872)$ & Girls $(n=786)$ & $p$ value & All patients $(n=1,658)$ \\
\hline \multicolumn{6}{|c|}{ Positive family history in first and second degree relatives } \\
\hline $\mathrm{CVD}^{\mathrm{a}}$ & [14] & $157(18.0)$ & $138(17.6)$ & NS & $295(17.8)$ \\
\hline Diabetes & {$[34,35]$} & $194(22.2)$ & $175(22.3)$ & NS & $369(22.3)$ \\
\hline $\mathrm{HbA}_{1 \mathrm{c}}$ above the target level ${ }^{\mathrm{b}}$ & {$[14,16]$} & $597(70.9)$ & $552(72.2)$ & NS & $1,149(71.4)$ \\
\hline LDL-cholesterol $>2.6 \mathrm{mmol} / \mathrm{l}$ & [14] & $206(30.2)$ & $247(39.3)$ & 0.001 & $453(34.5)$ \\
\hline HDL-cholesterol $<1.1 \mathrm{mmol} / 1$ & [14] & $65(9.2)$ & $29(4.5)$ & 0.001 & $94(6.9)$ \\
\hline Blood pressure $>90$ th percentile & {$[14,16,22]$} & $81(7.1)$ & $71(6.7)$ & NS & $152(6.9)$ \\
\hline BMI $>95$ th percentile & {$[14,16]$} & $41(4.7)$ & $30(3.9)$ & NS & $71(4.4)$ \\
\hline Persistent microalbuminuria & {$[14]$} & $7(1.2)$ & $2(0.4)$ & NS & $9(0.8)$ \\
\hline Smokers $^{\mathrm{c}}$ & [14] & $19(2.2)$ & $12(1.5)$ & NS & $31(3)$ \\
\hline$\geq 1$ of the risk factors above & & $750(85.4)$ & $675(85.9)$ & & $1,420(86)$ \\
\hline$\geq 2$ of the risk factors above & & $385(44.1)$ & $365(46.5)$ & NS & $750(45)$ \\
\hline$\geq 3$ of the risk factors above & & $126(14.4)$ & $124(15.8)$ & NS & $250(15)$ \\
\hline$\geq 4$ of the risk factors above & & $26(2.9)$ & $13(1.7)$ & NS & $39(2.4)$ \\
\hline
\end{tabular}

Values are $n(\%)$

${ }^{\mathrm{a}} \mathrm{CVD}$ events before 60 years of age

${ }^{\mathrm{b}}$ Target levels: $8.5 \%$ in $<6$-year-olds, $8 \%$ in $6-12$-year-olds and $7.5 \%$ in $>12$-year-olds

${ }^{\mathrm{c}}$ Among those $>12$ years of age 
Table 3 Number of participants who did not fulfil selected dietary recommendations or recommendations on physical activity and sedentary behaviours

\begin{tabular}{|c|c|c|c|c|}
\hline & References & Boys $(n=287)$ & Girls $(n=289)$ & All patients $(n=576)$ \\
\hline Fat $>30 \%$ of energy intake ${ }^{a}$ & {$[48]$} & $211(82)$ & $212(82)$ & $423(82)$ \\
\hline Saturated fat $>10 \%$ of energy intake ${ }^{a}$ & {$[20,48,49]$} & $250(97)$ & $252(97)$ & $502(97)$ \\
\hline Fibre intake $<25 \mathrm{~g} /$ day $^{\mathrm{a}}$ & {$[47,49]$} & $215(83)$ & $248(95)$ & $463(89)$ \\
\hline Fruit and vegetables $<500 \mathrm{~g} /$ day $^{\mathrm{a}}$ & {$[15]$} & $234(91)$ & $237(91)$ & $471(91)$ \\
\hline Sedentary activity $>2 \mathrm{~h} /$ day & {$[40]$} & $286(97.7)$ & $288(99.7)$ & $575(99.7)$ \\
\hline Television-viewing $>2 \mathrm{~h} /$ day & {$[40]$} & $119(41.5)$ & $126(43.6)$ & $245(42.5)$ \\
\hline Moderate physical activity $<1 \mathrm{~h} /$ day & {$[17]$} & $122(42.7)$ & $176(61.1)$ & $299(51.9)$ \\
\hline
\end{tabular}

Values are $n(\%)$

${ }^{\text {a }}$ Participants with missing data $n=58$

history of type 2 diabetes; (3) $\mathrm{HbA}_{1 \mathrm{c}}$ and LDL-cholesterol above target levels, plus BP above the 90th percentile.

Other relatively frequent combinations of risk factors were: (1) BP above 90th percentile and LDL-cholesterol above target level (4\% of all patients); (2) LDL-cholesterol above target level and HDL-cholesterol below target level (3\% of all patients); and (3) LDL-cholesterol above target level and BMI above the 95th percentile (3\%).

Frequency of pharmacotherapy A high proportion of the patients had dyslipidaemia. As many as $35 \%$ of the patients had LDL-cholesterol $>2.6 \mathrm{mmol} / \mathrm{l}$ (and ought to get lifestyle intervention, according to ADA treatment guidelines). Moreover, $10 \%$ had LDL-cholesterol $>3.4 \mathrm{mmol} / 1$ and at least one other cardiovascular risk factor, while $2 \%$ had LDL-cholesterol $>4.1 \mathrm{mmol} / \mathrm{l}$. These patients should be treated with lipid-lowering medication according to ADA treatment guidelines. However, only $0.2 \%$ of all the patients or $3 \%$ of those who should have been were receiving lipidlowering treatment (statins) in line with ADA guidelines.

Of our patients, $7 \%$ had BP above the 90th percentile and $4 \%$ above the 95 th percentile. Additionally, $1 \%$ had BP $>130 / 80,4 \%$ SBP $>130$ and $2 \%$ DBP $>80$. Prehypertension (90-95th percentile) should be treated with lifestyle intervention according to ADA treatment guidelines, while hypertension (BP $>95$ th percentile or $>130 / 80$ ) and prehypertension that does not reach target BP $(<90$ th percentile) within 3 to 6 months should be treated pharmacologically $[14,22]$. Only $0.3 \%$ of all our patients or $4 \%$ of those who should have been were receiving anti-hypertensive treatment according to ADA guidelines.

\section{Discussion}

The present study is a population-based study of cardiovascular risk factors among children and adolescents with type 1 diabetes mellitus treated by intensive insulin therapy.
In addition to the conventional cardiovascular risk factors, the study includes information both about family history of early CVD and diabetes, and about physical activity/ inactivity and diet. To our knowledge, only a few studies exist on the subject, most of which have not included family history in their risk factor analyses.

This study shows a high prevalence of cardiovascular risk factors, as defined by ADA, in Norwegian children and adolescents with type 1 diabetes. As many as $86 \%$ of the participants had one or more cardiovascular risk factor and $15 \%$ had multiple risk factors (three or more). This is of concern, as it is well recognised that CVD risk factors persist or track over time [5, 7, 23]. The frequency of CVD risk factors found by us is also higher than reported in another recent study on the subject [24]. The fact that we included some more risk factors in our analyses and that the cut-off values are not always the same in these two studies might explain some of this difference. However, physical activity, sedentary behaviour and dietary habits were not included in the multiple risk factor analysis in our study, yet if these had been included, the estimated overall frequency of CVD risk factors among the participants in our study would have been even higher.

The most frequently diagnosed risk factor was $\mathrm{HbA}_{1 \mathrm{c}}$ above the target level. There is increasing evidence of the influence of blood glucose control on the development of atherosclerosis in diabetes. The Oslo study follow-up demonstrated that long-term blood glucose control predicts coronary atherosclerosis, measured directly by intravascular ultrasound, in young childhood-onset type 1 diabetic patients with no symptoms of CVD [25]. A recent DCCT/ Epidemiology of Diabetes Interventions and Complications (EDIC) publication demonstrated that intensive diabetes therapy has long-term beneficial effects on the risk of cardiovascular events in patients with type 1 diabetes [26]. Yet another study identified $\mathrm{HbA}_{1 \mathrm{c}}>7.5 \%$ as a strong risk factor for increasing atherosclerotic plaque burden among young people with type 1 diabetes who are asymptomatic for coronary artery disease [27]. 
Cholesterol plays an important role in the initiation and progression of atherosclerosis [1, 28]. Increased levels of LDL-cholesterol were the second most frequently diagnosed risk factor in our analysis. The lipid measurements were taken non-fasting. Although non-fasting HDL-cholesterol levels can be slightly lower than fasting levels, this should not lead to misclassification of patients with low HDLcholesterol levels [29]. LDL-cholesterol can be measured using either indirect or direct methods [30]. In 30\% of our patients, LDL-cholesterol was measured by direct measurements, which avoids the need for fasting [29], while it was measured by the Friedewald equation, the most widely used indirect method [30], in $70 \%$ of the patients. Determination of calculated LDL-cholesterol should preferably be done in the fasting state. However, the Friedewald equation has been found to be fairly accurate in samples with triacylglycerol levels below $2.26 \mathrm{mmol} / 1$ (200 mg/dl) [29, 30]. Because of the low mean triacylglycerol levels in our patients, the fact that lipids were measured in the non-fasting state is unlikely to interfere with our results. Interestingly we found a higher prevalence of high LDL-cholesterol in girls than boys and higher prevalence of low HDL-cholesterol in boys than girls. This is the opposite of what is usually found in adults. Adult men usually have higher LDL-cholesterol than adult premenopausal women and both men and women show a tendency toward increased LDL-cholesterol with age. However, in children, the LDL- and HDL-cholesterol levels do not differ significantly between boys and girls [28]. In our material there was no significant difference in the proportion of participants with high LDL-cholesterol between prepubertal and pubertal children.

There are limited data on lipids in children and adolescents. However, the Cincinnati Myocardial Infarction and Hormone (CIMIH) family study found high LDLcholesterol $(>3.4 \mathrm{mmol} / \mathrm{l})$ in $9.5 \%$ and borderline LDLcholesterol $(>2.8 \mathrm{mmol} / \mathrm{l})$ in $15.1 \%$ of children and adolescents (age $2-19$ years; $n=232$ ) in their control cohort [31]. This is a much lower proportion than we found in the type 1 diabetic children and adolescents in our study, where $11 \%$ had LDL-cholesterol $>3.4 \mathrm{mmol} / 1$ and $24 \%$ had LDLcholesterol $>2.8 \mathrm{mmol} / 1$.

The studies published so far on cardiovascular risk factors in childhood and adulthood diabetes do not, in general, include family history in their analysis [24]. Almost one-third of our patients had a positive family history (first- and second-degree relatives) of one or more of the following: type 2 diabetes, heart attack and/or stroke before the age of 60 , while $22 \%$ had a positive family history of type 2 diabetes only. This is much higher than the known prevalence in the general population. A recent Norwegian study found the prevalence of known type 2 diabetes to be $3.2 \%$ [32]. A family history of early CVD (usually before age 55 years) is considered a risk factor for atherosclerosis in the general population [33] and at least two prospective studies of childhood-onset type 1 diabetes have demonstrated that a family history of type 2 diabetes is one of the most important factors for CVD [34, 35]. This emphasises the importance of including family history in the risk evaluation.

The proportion of patients in our study with BP above the 90th and 95th percentiles was within the range expected for the general population. It is, however, important to remember that this is elevated $\mathrm{BP}$, and as such a risk factor for CVD both in the diabetic and in the general population.

Among those with elevated BP in our study, isolated SBP elevation was the most common. White coat hypertension (WCH) may be more prevalent in the measure of SBP. Elevated pulse pressure may also be represented with elevated SBP and normal DBP. The pulse pressure increases with increased arterial stiffness and has been recognised as an important predictor of CVD [1]. Patients with type 1 diabetes have stiffer arteries than non-diabetic persons; higher pulse pressure, moreover, and a higher prevalence of isolated systolic hypertension have been reported in type 1 diabetic patients, compared with nondiabetic persons [1]. One recent study on non-diabetic participants found that $\mathrm{WCH}$ was associated with elevated arterial stiffness [36], while another recent study found an increased CVD risk in people with $\mathrm{WCH}$ compared with normotensive controls [37]. In light of this, isolated systolic hypertension in type 1 diabetic patients is certainly of clinical importance and should be followed-up carefully and treated if necessary.

As many as $96 \%$ of those who ought to have had antihypertensive treatment in line with ADA treatment guidelines were not receiving such treatment. Likewise, $97 \%$ of those who should have got lipid-lowering treatment in line with the same guidelines were not receiving it. It should, however, be born in mind that the results here are based on single measurements and more measurements should be done to verify the situation before putting children and adolescents on life-long medication.

Only $2 \%(n=31)$ of all patients, $3 \%$ of those aged $>12$ years old and $5 \%$ of those aged $>15$ years reported smoking. This is a much lower prevalence of smokers than that reported in other studies. In the Pathobiological Determinants of Atherosclerosis in Youth (PDAY) study [6], a 44\% prevalence of smoking in adolescents and young adults aged 15 to 34 years was reported. A recent study among young adults and adolescents with type 1 diabetes in Germany found $11 \%$ smokers in the 12 to 16 years age group and $35 \%$ in the 17 to 26 years age group [24]. It is not clear why we found fewer smokers among Norwegian children and adolescents. Smoking may, of course, simply be underreported. However, a decline in the incidence of smoking has been observed among adolescents with [9] and 
without [38] diabetes in Norway for the last few years. In the NCDQ study, smoking among patients above 15 years of age fell from $18 \%$ in 2001 to $5 \%$ in 2005 [9].

The American Heart Association has defined physical inactivity as an independent CVD risk factor [39] and the American Academy of Pediatrics (AAP) has recommended that children and adolescents decrease inactivity and specifically reduce television viewing to a maximum of $2 \mathrm{~h}$ per day [40]. In our study, $43 \%$ of the participants exceeded this limit.

Furthermore, almost $60 \%$ of our patients did not fulfil international recommendations for engaging in moderate physical activity for at least $1 \mathrm{~h}$ daily [17]. This is of concern. The National Heart, Lung and Blood Institute (NHLBI) Family Heart Study found that leisure time physical activity had a clearly favourable and televisionwatching an unfavourable association with anthropometric measurements and atherosclerosis risk factors in otherwise healthy adults [41]. Furthermore, some studies have shown that exercise patterns in children and adolescents extend into adulthood and sedentary adolescents tend to become sedentary adults [42-44]. Compared with Norwegian nondiabetic 9- and 15-year-olds [45], the diabetic patients in our study were less active, with $41 \%$ of our diabetic 9 -yearolds vs $17 \%$ of the non-diabetic 9 -year-olds and $61 \%$ of our diabetic 15 -year-olds vs $48 \%$ of the non-diabetic 15 -yearolds not fulfilling the recommendations. However, the comparisons should be viewed with caution due to different methods. A recent Finnish study reports that $46 \%$ of nondiabetic 15 -year-olds in northern Finland engage in physical activity for less than $1 \mathrm{~h}$ daily [46]. The same study found that $46 \%$ of Finnish adolescents watched television for more than $2 \mathrm{~h} /$ day, in comparison with $53 \%$ of the 15 year-old diabetic patients in our study.

In our study, most of the participants exceeded the recommendations for intake of energy from fat and saturated fat $[47,48]$, while most had a lower intake of fibre, fruits and vegetables compared with current recommendations [15, 47, 49]. This dietary pattern has negative characteristics in relation to atherosclerosis [10]. Saturated fat is the principal dietary determinant of LDL-cholesterol [20] and diabetic children and adolescents should be encouraged to decrease their intake of saturated fat.

The main strength of our study is that this is a population-based study with a high participation rate. Additionally, the study analysed a wide spectrum of cardiovascular risk factors, including family history of CVD and diabetes, as well as physical activity levels and dietary habits, all of which have not been widely investigated in the paediatric diabetes population.

In conclusion, this study is of major clinical relevance since it demonstrates a high frequency of atherogenic risk factors in children and adolescents with type 1 diabetes, even though the majority of patients are using modern, intensive insulin treatment. It therefore emphasises the importance of early and systematic screening for these risk factors. Early intervention should be considered in all patients at risk. With regard to lifestyle intervention, our results indicate that there is plenty of scope for increasing physical activity, reducing sedentary behaviour and changing dietary habits. So far, few patients in the relevant age group in Norway are being treated with lipid-lowering and anti-hypertensive drugs, making the discrepancy between a high prevalence of cardiovascular risk factors and the low treatment rate into a challenge for all paediatric diabetologists.

Acknowledgements The authors would like to thank all participants in the NCDQ project. K. Lande and K. Oppsiøn are thanked for centralised $\mathrm{HbA}_{1 \mathrm{c}}$ analysis. S. J. Kummrnes and B. Tyrdal are thanked for study coordinating functioning. This project was financed with the aid of EXTRA funds from the Norwegian Foundation for Health and Rehabilitation

Duality of interest The authors declare that there is no duality of interest associated with this manuscript.

\section{References}

1. Dahl-Jorgensen K, Larsen JR, Hanssen KF (2005) Atherosclerosis in childhood and adolescent type 1 diabetes: early disease, early treatment? Diabetologia 48:1445-1453

2. Skrivarhaug T, Bangstad HJ, Stene LC, Sandvik L, Hanssen KF, Joner G (2006) Long-term mortality in a nationwide cohort of childhood-onset type 1 diabetic patients in Norway. Diabetologia 49:298-305

3. Laing SP, Swerdlow AJ, Slater SD et al (2003) Mortality from heart disease in a cohort of 23,000 patients with insulin-treated diabetes. Diabetologia 46:760-765

4. Li S, Chen W, Srinivasan SR et al (2003) Childhood cardiovascular risk factors and carotid vascular changes in adulthood: the Bogalusa Heart Study. JAMA 290:2271-2276

5. Berenson GS, Srinivasan SR, Bao W, Newman WP III, Tracy RE, Wattigney WA (1998) Association between multiple cardiovascular risk factors and atherosclerosis in children and young adults. The Bogalusa heart study. N Engl J Med 338:1650-1656

6. Zieske AW, Malcom GT, Strong JP (2002) Natural history and risk factors of atherosclerosis in children and youth: the PDAY study. Pediatr Pathol Mol Med 21:213-237

7. Stamler J, Dyer AR, Shekelle RB, Neaton J, Stamler R (1993) Relationship of baseline major risk factors to coronary and allcause mortality, and to longevity: findings from long-term followup of Chicago cohorts. Cardiology 82:191-222

8. Miller J, Silverstein J (2003) Cardiovascular risk factors in childhood diabetes. Endocrinologist 13:394-407

9. Margeirsdottir H, Larsen J, Brunborg C, Dahl-Jorgensen K (2006) Nation-wide improvement in $\mathrm{HbA}_{1 \mathrm{c}}$ and complication screening in a benchmarking project in childhood diabetes. A prospective national quality study. Pediatr Diabetes 7(Suppl 5):18. (Abstr)

10. Overby NC, Flaaten V, Veierod MB, Bergstad I, Margeirsdottir H, Dahl-Jorgensen K (2007) Children and adolescents with type 1 diabetes eat more atherosclerosis-prone diet than healthy control subjects. Diabetologia 50:307-316 
11. Andersen LF, Pollestad ML, Jacobs DRJ, Lovo A, Hustvedt BE (2005) Validation of a pre-coded food diary used among 13-yearolds: comparison of energy intake with energy expenditure. Public Health Nutr 8:1315-1321

12. Andersen SA, Solberg M (2005) Methods to measure physical activity. Development and validation of a questionnaire used in children. Report from Directorate of Health and Social Affairs, Oslo

13. Hustvedt BE, Christophersen A, Johnsen LR et al (2004) Description and validation of the ActiReg: a novel instrument to measure physical activity and energy expenditure. Br J Nutr 92:1001-1008

14. American Diabetes Association (2005) Standards of medical care in diabetes. Diabetes Care 28:S4-S36

15. Andersen LF, Overby N, Lillegaard IT (2004) Intake of fruit and vegetables among Norwegian children and adolescents. Tidsskr Nor Laegeforen 124:1396-1398

16. No authors listed (2000) Consensus guidelines for the management of children and adolescents with diabetes. ISPAD (International Society for Pediatric and Adolescent Diabetes). Medical Forum International, Zeist

17. Strong WB, Malina RM, Blimkie CJ et al (2005) Evidence based physical activity for school-age youth. J Pediatr 146:732-737

18. American Diabetes Association (2003) Nutrition principles and recommendations in diabetes. Diabetes Care 26:S51-S61

19. Wassermann DH, Zimmman B (1994) Exercise in individuals with diabetes mellitus. Diabetes Care 17:924-937

20. Franz MJ, Bantle JP, Beebe CA et al (2002) Evidence-based nutrition principles and recommendations for the treatment and prevention of diabetes and related complications. Diabetes Care 25:148-198

21. Cole TJ, Bellizzi MC, Flegal KM, Dietz WH (2000) Establishing a standard definition for child overweight and obesity worldwide: international survey. BMJ 320:1240-1243

22. National High Blood Pressure Education Program Working Group on High Blood Pressure in Children and Adolescents (2004) The fourth report on the diagnosis, evaluation, and treatment of high blood pressure in children and adolescents. Pediatrics 114:555-576

23. Williams CL, Hayman LL, Daniels SR et al (2002) Cardiovascular health in childhood: a statement for health professionals from the Committee on Atherosclerosis, Hypertension, and Obesity in the Young (AHOY) of the Council on Cardiovascular Disease in the Young, American Heart Association. Circulation 106:143-160

24. Schwab KO, Doerfer J, Hecker W et al (2006) Spectrum and prevalence of atherogenic risk factors in 27,358 children, adolescents, and young adults with type 1 diabetes: cross-sectional data from the German diabetes documentation and quality management system (DPV). Diabetes Care 29:218-225

25. Larsen J, Brekke M, Sandvik L, Arnesen H, Hanssen KF, DahlJorgensen K (2002) Silent coronary atheromatosis in type 1 diabetic patients and its relation to long-term glycemic control. Diabetes 51:2637-2641

26. Nathan DM, Cleary PA, Backlund JY et al (2005) Intensive diabetes treatment and cardiovascular disease in patients with type 1 diabetes. N Engl J Med 353:2643-2653

27. Snell-Bergeon JK, Hokanson JE, Jensen L et al (2003) Progression of coronary artery calcification in type 1 diabetes: the importance of glycemic control. Diabetes Care 26:2923-2928

28. Remaley AT, McNamara JR, Warnick GR (2005) Lipids and lipoproteins. In: Bishop ML, Fody EP, Schoeff LE (eds) Clinical chemistry: principles, procedures, correlations. 5th edn. Lippincott Williams \& Wilkins, Philadelphia, pp 282-313

29. Àbel G, Laposata M (2002) Lipids and lipoproteins. In: McClatchey KD (ed) Clinical laboratory medicine. 2nd edn. Lippincott Williams \& Wilkins, Philadelphia, pp 306-321

30. Rifai N, Warmick G (2006) Lipids, lipoproteins, apolipoproteins, and other cardiovascular risk factors. In: Burtis C, Ashwood E, Bruns D (eds) TIETZ textbook of clinical chemistry and molecular diagnostics. 4th edn. Elsevier, St Louis, pp 903-970
31. Diller PM, Huster GA, Leach AD, Laskarzewski PM, Sprecher DL (1995) Definition and application of the discretionary screening indicators according to the National Cholesterol Education Program for Children and Adolescents. J Pediatr 126:345-352

32. Midthjell K, Kruger O, Holmen J et al (1999) Rapid changes in the prevalence of obesity and known diabetes in an adult Norwegian population. The Nord-Trondelag health surveys: 1984-1986 and 1995-1997. Diabetes Care 22:1813-1820

33. Grundy SM, Balady GJ, Criqui MH et al (1997) Guide to primary prevention of cardiovascular diseases. A statement for healthcare professionals from the task force on risk reduction. American Heart Association Science Advisory and Coordinating Committee. Circulation 95:2329-2331

34. Erbey JR, Kuller LH, Becker DJ, Orchard TJ (1998) The association between a family history of type 2 diabetes and coronary artery disease in a type 1 diabetes population. Diabetes Care 21:610-614

35. Makimattila S, Ylitalo K, Schlenzka A et al (2002) Family histories of type II diabetes and hypertension predict intima-media thickness in patients with type I diabetes. Diabetologia 45:711-718

36. de Simone G, Schillaci G, Chinali M, Angeli F, Reboldi GP, Verdecchia P (2007) Estimate of white-coat effect and arterial stiffness. J Hypertens 25:827-831

37. Gustavsen PH, Hoegholm A, Bang LE, Kristensen KS (2003) White coat hypertension is a cardiovascular risk factor: a 10 -year follow-up study. J Hum Hypertens 17:811-817

38. No authors listed (2007) The use of tobacco in the secondary school. Report from Directorate for Health and Social affairs, Oslo

39. Fletcher GF, Blair SN, Blumenthal J et al (1992) Statement on exercise. Benefits and recommendations for physical activity programs for all Americans. A statement for health professionals by the Committee on Exercise and Cardiac Rehabilitation of the Council on Clinical Cardiology, American Heart Association. Circulation 86:340-344

40. American Academy of Pediatrics, Committee on Public Education (2001) American Academy of Pediatrics: children, adolescents, and television. Pediatrics 107:423-426

41. Kronenberg F, Pereira MA, Schmitz MK et al (2000) Influence of leisure time physical activity and television watching on atherosclerosis risk factors in the NHLBI Family Heart Study. Atherosclerosis 153:433-443

42. Raitakari OT, Porkka KV, Taimela S, Telama R, Rasanen L, Viikari JS (1994) Effects of persistent physical activity and inactivity on coronary risk factors in children and young adults. The cardiovascular risk in young Finns study. Am J Epidemiol 140:195-205

43. Telama R, Yang X, Laakso L, Viikari J (1997) Physical activity in childhood and adolescence as predictor of physical activity in young adulthood. Am J Prev Med 13:317-323

44. Telama R, Yang X, Viikari J, Valimaki I, Wanne O, Raitakari O (2005) Physical activity from childhood to adulthood: a 21-year tracking study. Am J Prev Med 28:267-273

45. Klasson-Heggebo L, Anderssen SA (2003) Gender and age differences in relation to the recommendations of physical activity among Norwegian children and youth. Scand J Med Sci Sports 13:293-298

46. Tammelin T, Ekelund U, Remes J, Nayha S (2007) Physical activity and sedentary behaviors among Finnish youth. Med Sci Sports Exerc 39:1067-1074

47. No authors listed (2005) Nordic nutrition recommendations 2004. Integrating nutrition and physical activity. Nordic Council of Ministers, Cophenhagen, Norden

48. Mann JI, De Leeuw I, Hermansen K et al (2004) Evidence-based nutritional approaches to the treatment and prevention of diabetes mellitus. Nutr Metab Cardiovasc Dis 14:373-394

49. Krauss RM, Eckel RH, Howard B et al (2000) AHA dietary guidelines: revision 2000: a statement for healthcare professionals from the Nutrition Committee of the American Heart Association. Circulation 102:2284-2299 